Check for updates

Cite this: Mater. Adv., 2020 1,899

Received 30th March 2020, Accepted 17th June 2020

DOI: $10.1039 / \mathrm{d} 0 \mathrm{ma} 00145 \mathrm{~g}$

rsc.li/materials-advances

\title{
Photo-induced guest-host interactions produce grain boundaries between smectic blocks $\dagger$
}

\begin{abstract}
Atsushi Yoshizawa (D) * and Sakie Obata
Photo-induced isomerization of an azobenzene unit not only induces phase transition between two different phases but also brings marked changes in the physical properties of solids. We prepared a symmetric trimer possessing an azobenzene unit, 4,4'-bis\{9-[4-(5-octylpyrimidin-2-yl)phenyloxy]nonyloxy\}azobenzene (I), and investigated the phase transition behaviour of trimer $\mathbf{I}$ and that of its binary mixture with a host liquid crystal. Trimer I exhibited three crystalline phases on cooling. Photo-induced isothermal crystal-liquid transition occurred only in the highest temperature crystalline phase through the trans-cis isomerization of the azobenzene unit. A binary mixture of trimer I (20 wt\%) and a host liquid crystal ( $80 \mathrm{wt} \%$ ) was found to exhibit grain boundaries consisting of nematic liquid crystals between smectic $C$ blocks during a cooling process under UV irradiation. We explain the phase separation in terms of guest-host interactions between the photoinduced cis-trimer and its surrounding host liquid-crystalline molecules.
\end{abstract}

\section{Introduction}

Phase-separation phenomena in soft matter have attracted considerable attention because of their importance in the understanding of the molecular organization. ${ }^{1-4}$ Phase separation observed for a liquid-crystalline mixture is the coexistence of different phases which appear in the temperature sequence of the mixture. On the other hand, some chiral frustrated liquid-crystalline phases, i.e., blue phases and twist grain boundary (TGB) phases, have defects in which the molecular orientation is thought to be isotropic. Anisotropy and isotropy coexist in these frustrated phases. TGB phases were predicted by de Gennes ${ }^{5}$ and later by Renn and Lubensky ${ }^{6}$ to be a result of the competition between twist deformation and the formation of a layer structure. The first experimental observation of a TGB phase was reported by Goodby et al. ${ }^{7,8}$ It was shown to exhibit blocks of smectic A molecular order mediated by screw dislocations. Such competition is thought to produce a new type of phase separation in which smectic blocks and liquid-like regions coexist. Recently, a twist-bend nematic phase $\left(\mathrm{N}_{\mathrm{TB}}\right)$ showing domains of opposite handedness was observed for members of achiral $\alpha, \omega$-bis- 4 -( $4^{\prime}$-cyanobiphenyl)alkanes with flexible odd-numbered methylene spacers. ${ }^{9}$ The molecules form a helix. The director is tilted with respect to the helical

Department of Frontier Materials Chemistry, Graduate School of Science and Technology, Hirosaki University, 3 Bunkyo-cho, Hirosaki, Aomori 036-8561, Japan. E-mail: ayoshiza@hirosaki-u.ac.jp

$\dagger$ Electronic supplementary information (ESI) available. See DOI: 10.1039/ d0ma00145g axis in the $\mathrm{N}_{\text {Тв }}$ phase. ${ }^{10,11}$ Dozov proposed that inducing some twists can produce a spontaneous bend. Moreover, he predicted that the $\mathrm{N}_{\text {TB }}$ phase can exist for bent molecules. ${ }^{12}$ The $\mathrm{N}_{\mathrm{TB}}$ phase has been observed for liquid crystal dimers with an odd-numbered methylene spacer, ${ }^{13}$ bent-core liquid crystals ${ }^{14}$ and oligomers. ${ }^{15,16}$ Furthermore, a heliconical tilted smectic $\mathrm{C}\left(\mathrm{SmC}_{\mathrm{TB}}\right)$ phase has been discovered for achiral asymmetric dimers with an odd number of atoms in the spacer. ${ }^{17}$ However, to the best of our knowledge, a bend grain boundary phase has never been found so far. ${ }^{18,19}$ If a bend deformation is induced in a smectic phase under an external field, a field-induced smectic phase accompanying the formation of grain boundaries can be formed.

We investigated dynamic behaviour of liquid-crystalline molecules in smectic phases using solid-state C-13 NMR. ${ }^{20}$ The NMR studies revealed the following conclusions: (1) cooperative motion of the core parts contributes to the orientational order of the molecules in each layer and (2) interlayer permeation of tails causes correlation between adjacent layers. These conclusions make it possible to design various kinds of liquid-crystalline oligomers stabilizing frustrated phases. ${ }^{21,22}$ For example, we reported that a chiral dimer in which two phenylpyrimidine units are connected with optically active 3-methyladipic acid induces TGB phases in the mixture with smectic liquid crystals. $^{23}$ If we design a photo-responsive guest molecule which intercalates to the adjacent layers composed of host smectic molecules, the photo-induced conformation change of the guest molecule can cause deformation of the layer due to the guest-host interactions (Fig. 1). In this report, we designed a symmetric trimer possessing an azobenzene unit and two phenylpyrimidine cores, and investigated the phase 


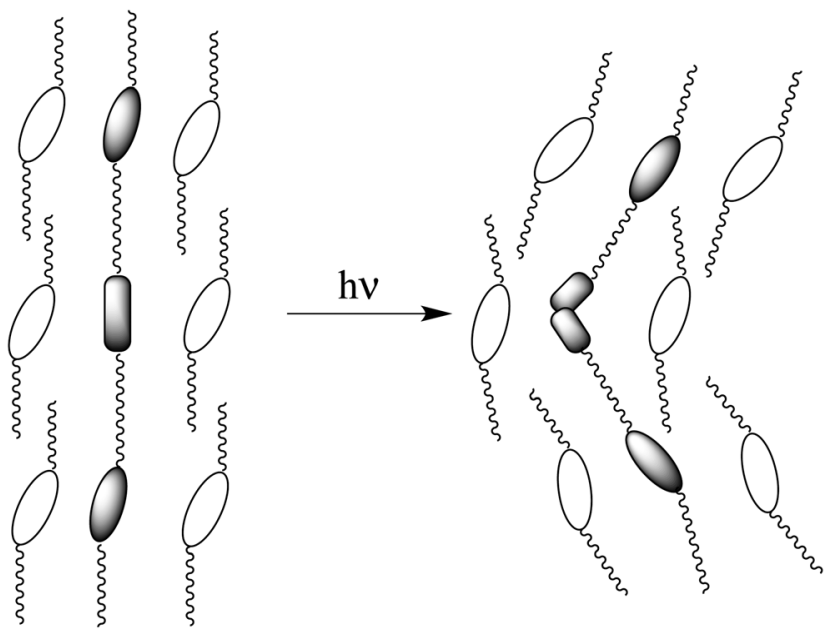

Fig. 1 Design concept of the trimer for producing a bend deformation in a smectic phase.

transition behaviour of the trimer and that of its mixture with a host liquid crystal. Photo-induced isomerization of an azobenzene unit is well known to cause a remarkable change in the physical properties of liquid crystals. ${ }^{24-28}$ Recently, the photo-induced crystal-melt and crystal-crystal transitions have attracted much attention. ${ }^{29-31} \mathrm{~A}$ photo-induced crystal-liquid transition was observed in many azobenzene-containing systems, which in many cases, indicates photochemical reactions. ${ }^{32}$ However, this in the present study indicates a photo-induced isothermal phase transition. Photo-induced cis-azobenzene derivatives form a bent molecular shape with the twisted azobenzene unit. Phenylpyrimidine is a well-known rigid core to stabilize a smectic phase via core-core interactions. Guest-host interactions between the photo-induced bent-shaped trimer and the surrounding host molecules are expected to occur. We report here that: (1) the newly designed trimer exhibits a photo-induced isothermal crystal-liquid transition and (2) the mixture with a host liquid crystal exhibits a smectic $\mathrm{C}(\mathrm{SmC})$ phase accompanying the formation of grain boundaries under UV irradiation.

\section{Experimental}

\section{Materials}

2-(4-Hydroxyphenyl)-5-octylpyrimidine (Midori Kagaku Co., Ltd) and 4,4'-dihydroxyazobenzene (Tokyo Chemical Industry Co., Ltd) were used as starting materials. 2-\{4-(4-Pentylphenyl)phenyl $\}-5-$ hexylpyrimidine was provided by Japan Energy Corporation. The purity of the final compound was confirmed by elemental analysis (EA 1110; CE Instruments Ltd). Infrared (IR) spectroscopy (FTS-30; Bio-Rad Laboratories Inc.) and proton nuclear magnetic resonance ( ${ }^{1} \mathrm{H}$ NMR) spectroscopy (JNM-ECA500; JEOL) were used to elucidate the structure of the final product.

\section{4,4'-Bis $\{9-[4-(5-o c t y l p y r i m i d i n-2-y l) p h e n y l o x y]$ nonyloxy $\}$ azobenzene (I)}

Potassium carbonate $(64 \mathrm{mg}, 0.46 \mathrm{mmol})$ was added to a solution of $4,4^{\prime}$-dihydroxyazobenzene $(100 \mathrm{mg}, 0.47 \mathrm{mmol})$ and 1,9-dibromononane (350 $\mathrm{mg}, 1.22 \mathrm{mmol}$ ) in cyclohexanone $(15 \mathrm{~mL})$. The reaction mixture was stirred at $100{ }^{\circ} \mathrm{C}$ for $5 \mathrm{~h}$ and $120{ }^{\circ} \mathrm{C}$ for $5 \mathrm{~h}$. After filtration of the precipitate, the solvent was removed by evaporation. The residue was added to alkaline water. The solution was extracted using toluene. The organic phase was dried over magnesium sulfate, filtered, and concentrated. Then the residue was purified using column chromatography on silica gel with toluene as the eluent. The obtained yellow solid was washed with hexane to give 4,4'-bis(9-bromononyloxy)azobenzene. Yield: $62 \mathrm{mg}$ (21\%). m.p.: $114.1-115.8{ }^{\circ} \mathrm{C}$.

Potassium carbonate $(28 \mathrm{mg}, 0.20 \mathrm{mmol})$ was added to a solution of $4,4^{\prime}$-bis(9-bromononyloxy)azobenzene $(50 \mathrm{mg}$, $0.08 \mathrm{mmol}$ ) and 2-(4-hydroxyphenyl)-5-octylpyrimidine (56 mg, $0.20 \mathrm{mmol}$ ) in cyclohexanone $(10 \mathrm{~mL})$. The reaction mixture was stirred at $100{ }^{\circ} \mathrm{C}$ for $10 \mathrm{~h}$ and $120{ }^{\circ} \mathrm{C}$ for $3.5 \mathrm{~h}$. After filtration of the precipitate, the solvent was removed by evaporation. Then the residue was washed with hot ethanol and recrystallized from toluene to give the desired compound. Yield: $38 \mathrm{mg}$ (46\%). m.p.: 143.9-145.5 ${ }^{\circ} \mathrm{C}$.

${ }^{1} \mathrm{H}$ NMR $\left(500 \mathrm{MHz}, \mathrm{CDCl}_{3}\right.$, TMS): $\delta_{\mathrm{H}} / \mathrm{ppm}: 8.56(\mathrm{~s}, 4 \mathrm{H}, \mathrm{Ar}-\mathrm{H})$, $8.33(\mathrm{~d}, 4 \mathrm{H}, \mathrm{Ar}-\mathrm{H}, J=9.1 \mathrm{~Hz}), 7.85(\mathrm{~d}, 4 \mathrm{H}, \mathrm{Ar}-\mathrm{H}, J=8.6 \mathrm{~Hz}), 6.98$ (d, $4 \mathrm{H}, \mathbf{A r}-\mathrm{H}, J=9.0 \mathrm{~Hz}$ ), 6.97 (d, $4 \mathrm{H}, \mathbf{A r}-\mathrm{H}, J=9.2 \mathrm{~Hz}), 4.03$ $\left(\mathrm{t}, 8 \mathrm{H},-\mathrm{OCH}_{2^{-}}, J=6.6 \mathrm{~Hz}\right), 2.59\left(\mathrm{t}, 4 \mathrm{H}, \mathrm{Ar}-\mathrm{CH}_{2^{-}}, J=7.7 \mathrm{~Hz}\right), 1.82$ (quint, 8H, aliphatic-H, $J=7.0 \mathrm{~Hz}$ ), 1.63 (quint, $4 \mathrm{H}$, aliphatic-H, $J=7.3 \mathrm{~Hz}), 1.53-1.45(\mathrm{~m}, 8 \mathrm{H}$, aliphatic-H), $1.43-1.22(\mathrm{~m}, 32 \mathrm{H}$, aliphatic-H), $0.88\left(\mathrm{t}, 6 \mathrm{H},-\mathrm{CH}_{3}, J=6.9 \mathrm{~Hz}\right)$. IR (KBr): $\nu \mathrm{cm}^{-1}$ : 2919， 2851 (C-Hstr), 1604，1583，1430 (C=Cstr, C=Nstr), 1251 (C-Ostr). Elemental analysis (\%): calc. for $\mathrm{C}_{66} \mathrm{H}_{90} \mathrm{~N}_{6} \mathrm{O}_{4}$ : C, 76.85 H, 8.79; N, 8.15. Found C, 76.72; H, 9.07; N, 8.08.

\section{Physical properties}

The initial phase assignments and the corresponding transition temperatures for the final compound was determined by thermal optical microscopy using a polarizing microscope (BX-51; Olympus Optical Co. Ltd.) equipped with a temperature control unit (LK-600PM; Japan High Tech). The temperatures and enthalpies of transition for trimer 1 were investigated using differential scanning calorimetry (DSC, DSC 6200 Seiko Instruments Inc.). The material was studied at a scanning rate of $5{ }^{\circ} \mathrm{C} \mathrm{min}^{-1}$ for both cooling and heating after being encapsulated in aluminum pans. Homogeneous configuration cells were purchased from EHC Co., Ltd. The inner surfaces were coated with a polyimide aligning agent and buffed unidirectionally. A sample was irradiated using a $365 \mathrm{~nm} \mathrm{UV}$ light source. We checked whether UV irradiation causes photothermal heating. We measured the temperature of the plate in the thermal control unit with UV irradiation using a digital thermometer. No photothermal heating was detected. We also observed the N-I transition temperature of 4-cyano-4'-pentylbiphenyl (5CB) with UV irradiation. UV irradiation did not affect the inherent phase transition temperature. The UV-Vis absorption spectra of the chloroform solution of trimer 1 ( $2.5 \times$ $10^{-5} \mathrm{M}$ ) were recorded on a UV-vis spectrometer (V-670; JASCO Co. Ltd.) in the transmission mode at room temperature. The thermal cis-trans isomerization rate of trimer $\mathbf{I}$ was obtained as follows. Trimer I in a chloroform solution at a concentration of 
$2.5 \times 10^{-5} \mathrm{M}$ was irradiated with $365 \mathrm{~nm} \mathrm{UV}$ at a power of $10 \mathrm{~mW} \mathrm{~cm} \mathrm{~cm}^{-2}$ for $10 \mathrm{~s}$. Then, we observed the electronic spectrum change at $360 \mathrm{~nm}$ at room temperature.

\section{Results and discussion}

\section{Trimer I}

We prepared trimer I in which an azobenzene unit and two phenylpyrimidine units are connected with flexible oddnumbered methylene spacers. Although it has three mesogenic units within a molecule, it showed no liquid-crystalline properties. Fig. 2 shows the molecular structure of trimer I with the phase transition temperatures. Trimer I exhibited three crystalline phases, i.e., Cry1, Cry2 and Cry3, upon cooling. The sample on a glass plate with a cover glass was exposed to UV irradiation in Cry1. Fig. 3 shows the optical textures of trimer I before and after $365 \mathrm{~nm}$ UV irradiation at $10 \mathrm{~mW} \mathrm{~cm}^{-2}$ in Cry1. The crystal changed to isotropic liquid in about $30 \mathrm{~s}$ with the UV irradiation at $T-T_{\text {Iso-Cry } 1}=-0.8 \mathrm{~K}$ (Fig. $3(\mathrm{a})$ and (b)). This transformation is not attributed to photothermal heating as described in the Experimental section. When the light was switched off, Cry1 phase reappeared in 1s. However, the reappeared Cry1 consisted of smaller domains than the original Cry1 (Fig. 3(c)). When the sample was irradiated with the UV light at $T-T_{\text {Iso-Cry1 }}=-1.5 \mathrm{~K}$, half of the sample changed to the isotropic liquid, whereas the other half changed to an intermediate state (Fig. 4(a) and (b)). When the UV light was turned off, the isotropic region changed to Cry1 consisting of the smaller domains, on the other hand, the intermediate state returned to the original Cry1 phase (Fig. 4(c)). To confirm reversibility, when the sample (Fig. 4(c)) was irradiated again, it changed to the same texture as shown in Fig. 4(b). Repetition of the on-off cycle decreases the size of the intermediate state, and finally, the most of the area was transformed into isotropic liquid with the UV irradiation (Fig. S1, ESI $\dagger$ ). The Cry1 phase consisting of the smaller domains

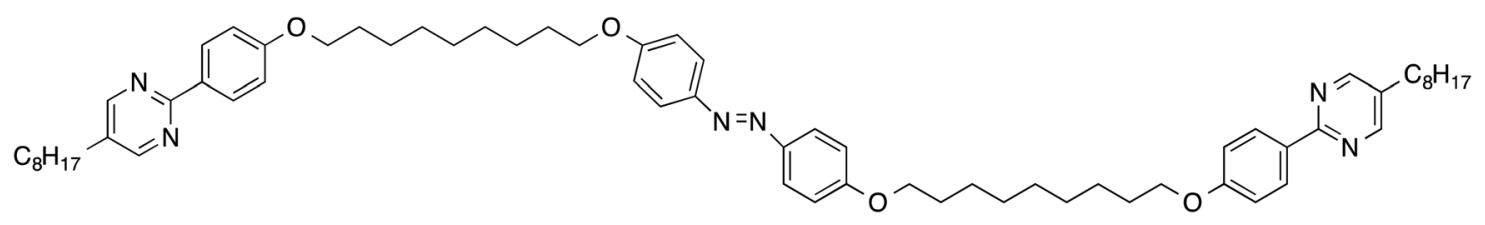

I: Iso $144.3^{\circ} \mathrm{C}\left(76.7 \mathrm{~kJ} \mathrm{~mol}^{-1}\right) \mathrm{Cry} 1126.9^{\circ} \mathrm{C}\left(5.81 \mathrm{~kJ} \mathrm{~mol}^{-1}\right) \mathrm{Cry} 267.3^{\circ} \mathrm{C}\left(29.5 \mathrm{~kJ} \mathrm{~mol}^{-1}\right) \mathrm{Cry} 3$

Fig. 2 Molecular structure of trimer I with the cooling phase transition properties.

(a)

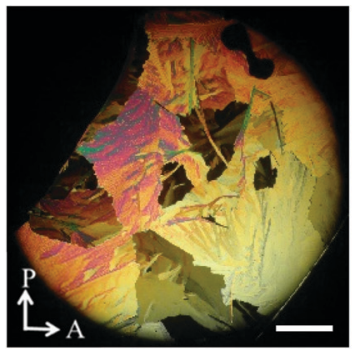

(b)

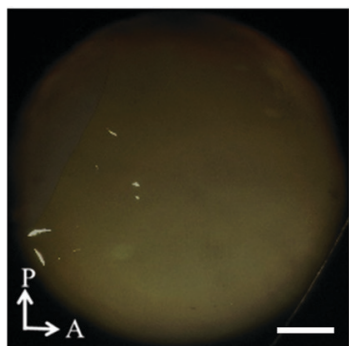

(c)

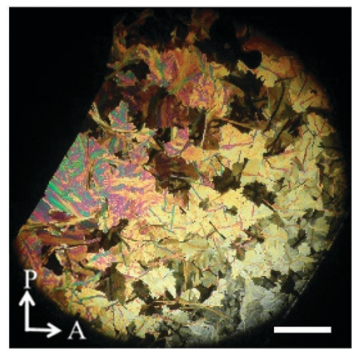

Fig. 3 Optical texture of: (a) trimer I in the Cry1 phase at $T-T_{\text {Iso-Cry } 1}=-0.8 \mathrm{~K}$, (b) under $365 \mathrm{~nm}$ UV irradiation at $10 \mathrm{~mW} \mathrm{~cm}^{-2}$ and (c) after the UV light was turned off. Scale bars correspond to $500 \mu \mathrm{m}$.

(a)

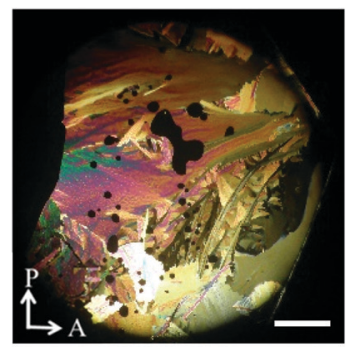

(b)

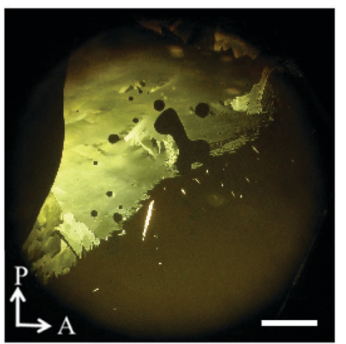

(c)

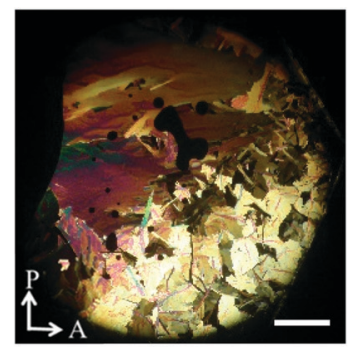

Fig. 4 Optical texture of: (a) trimer I in Cry1 phase at $T-T_{\text {Iso-Cry } 1}=-1.5 \mathrm{~K}$, (b) under $365 \mathrm{~nm}$ UV irradiation at $10 \mathrm{~mW} \mathrm{~cm}^{-2}$ and (c) after the UV light was turned off. Scale bars correspond to $500 \mu \mathrm{m}$. 
was not observed during the thermal phase transition between the isotropic liquid and Cry1. The photo-induced phase separation was observed in the lower temperature range of Cry1, however, it was not detected in Cry2 or in Cry3.

In order to demonstrate how photo-irradiation affects the azobenzene unit of trimer 1, we measured the UV-vis spectra of trimer $1\left(2.5 \times 10^{-5} \mathrm{M}\right)$ in a chloroform solution under UV light with a wavelength of $365 \mathrm{~nm}$ as a function of irradiation intensity (Fig. S2, ESI $\dagger$ ). As the irradiation intensity increased, absorbance at $360 \mathrm{~nm}$ associated with the $\pi-\pi^{*}$ transition of the trans form decreased whereas an absorbance at $450 \mathrm{~nm}$ associated with the weak symmetry forbidden $n-\pi *$ transition of the cis form increased, revealing that the trans-cis photoisomerization of the azobenzene unit occurs. In order to evaluate the stability of the cis isomer, we measured the thermal cis-trans isomerization rate of trimer $\mathbf{1}$ in a chloroform solution at room temperature. The first order rate constant was found to be $8 \times 10^{-4} \mathrm{~s}^{-1}$. On the other hand, the liquid to Cry1 transition of trimer I occurred immediately after the UV light was turned off. There is no marked temperature dependence of the transition rate. We used a polarized optical microscope equipped with a halogen lamp to observe the transition phenomena. Not only high temperature but also visible light might accelerate the cis-trans isomerization.

The crystal to isotropic liquid transition of trimer $\mathbf{I}$ is explained in terms of the trans-cis photoisomerization of the azobenzene unit. The isotropic to crystal transition occurred through the cistrans isomerization to produce the crystal consisting of the smaller domains. According to Barrett et al., ${ }^{31}$ the photochemical effect of the cis to trans isomerization of azobenzene involves a single crystal to polycrystal transformation due to the large structural change. As decreasing temperature in Cry1, the cis over trans ratio is thought to decrease, which might decrease the photo-induced transition area. As shown in Fig. 4, the photoinduced Cry1-Iso transition occurs via the intermediate state where the cis over trans ratio is too small to transform the isotropic liquid. The photo-induced transition between solid and liquid, and that in solid phases are of interest for potential applications. ${ }^{33-35}$ Modification of the molecular structure is now in progress for obtaining materials exhibiting the photo-induced Cry-Iso phase transition in a wide temperature range.

\section{Binary system}

Then, we designed a binary system of trimer I and a host liquid crystal. We used compound II as a host liquid crystal. Compound II exhibiting $\mathrm{N}$ and SmC phases with a wide temperature range is known to be a suitable component for preparing ferroelectric liquid crystal mixtures. ${ }^{36}$ The molecular structure of compound II with phase transition temperatures are shown

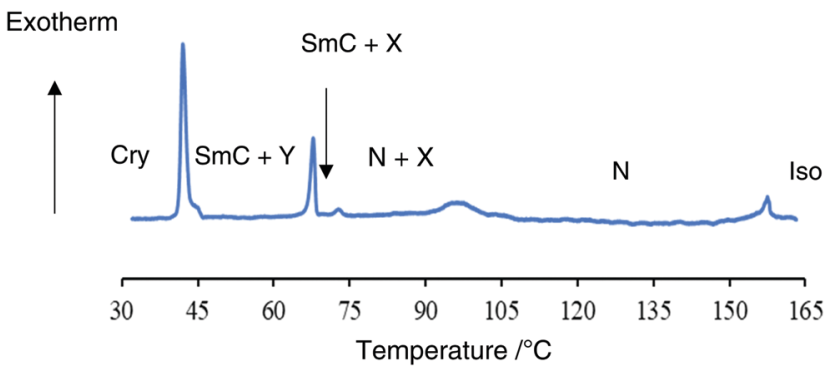

Fig. 6 Cooling DSC thermogram of a mixture of trimer I (20 wt\%) and compound II (80 wt\%). The cooling rate was $5{ }^{\circ} \mathrm{C} \mathrm{min}^{-1}$.

in Fig. 5. We prepared some binary mixtures of trimer $\mathbf{I}$ and compound II with different composition ratios. We demonstrate transition properties of a mixture containing $20 \mathrm{wt} \%$ of trimer I because it showed evident photo-induced effects. Fig. 6 shows a cooling DSC thermogram of the mixture. On cooling, the isotropic liquid changed to the $\mathrm{N}$ phase at $158{ }^{\circ} \mathrm{C}$ $\left(0.93 \mathrm{~kJ} \mathrm{~mol}^{-1}\right)$, and then a new phase denoted as $\mathrm{X}$ began to appear at $96{ }^{\circ} \mathrm{C}\left(2.57 \mathrm{~kJ} \mathrm{~mol}^{-1}\right)$ and it coexisted with the $\mathrm{N}$ phase. The broad peak and the relatively large enthalpy change for the $\mathrm{N}-\mathrm{X}$ transition indicate that the $\mathrm{X}$ phase is a crystalline phase. The appearance of the $\mathrm{X}$ phase results from interactions between trans-trimer I and the surrounding host molecules. The remaining $\mathrm{N}$ phase changed to a SmC phase at $73{ }^{\circ} \mathrm{C}$ $\left(0.27 \mathrm{~kJ} \mathrm{~mol}^{-1}\right)$. The $\mathrm{X}$ phase changed to another crystalline phase denoted as $\mathrm{Y}$ phase at $68{ }^{\circ} \mathrm{C}\left(2.81 \mathrm{~kJ} \mathrm{~mol}^{-1}\right)$. The SmC and $\mathrm{Y}$ phases were crystallized at $42{ }^{\circ} \mathrm{C}\left(8.43 \mathrm{~kJ} \mathrm{~mol}^{-1}\right)$. The optical textures of the mixture on a glass plate during a cooling process are shown in Fig. S3 (ESI $\dagger$ ).

Then the mixture confined in a $5 \mu \mathrm{m}$ homogeneously aligned cell was irradiated with $365 \mathrm{~nm}$ UV light at a power of $20 \mathrm{~mW} \mathrm{~cm}{ }^{-2}$ in the $\mathrm{N}$ phase at $153.5{ }^{\circ} \mathrm{C}$ (Fig. 7(a)). The $\mathrm{N}$ phase changed to the optically isotropic phase in about $1 \mathrm{~s}$. The texture of the photo-induced isotropic phase was the same as that of the higher temperature isotropic liquid, revealing that the texture change corresponds to the photo-induced isothermal $\mathrm{N}$ to isotropic liquid phase transition. When the light was turned off, the isotropic liquid returned to the $\mathrm{N}$ phase in about $1 \mathrm{~s}$ reversibly. On the other hand, when the mixture was irradiated with UV light at $114.2{ }^{\circ} \mathrm{C}$, the colour of the mixture changed from red to yellow (Fig. 7(b)), indicating that the optical anisotropy decreases. The colour change induced by the UV irradiation was also reversible. These results are explained in terms of the trans-cis photoisomerization of the azobenzene unit.

The mixture exhibiting coexistence of the $\mathrm{N}$ and $\mathrm{X}$ phases was irradiated with $365 \mathrm{~nm}$ UV light at a power of $20 \mathrm{~mW} \mathrm{~cm}^{-2}$

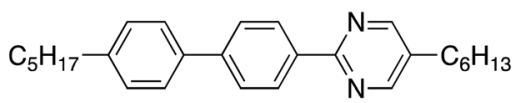

II: Iso $162.7^{\circ} \mathrm{C}\left(0.84 \mathrm{~kJ} \mathrm{~mol}^{-1}\right) \mathrm{N} 80.7^{\circ} \mathrm{C}\left(0.30 \mathrm{~kJ} \mathrm{~mol}^{-1}\right) \mathrm{SmC} 41.1^{\circ} \mathrm{C}\left(6.26 \mathrm{~kJ} \mathrm{~mol}^{-1}\right)$ Cry

Fig. 5 Molecular structure of compound II with the cooling transition temperatures. 
(a)

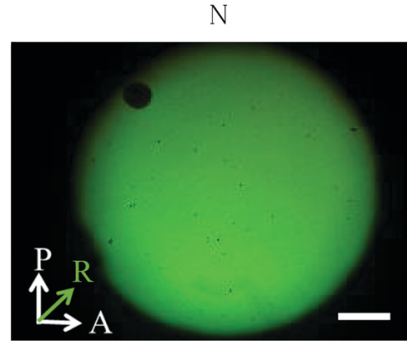

N

(b)

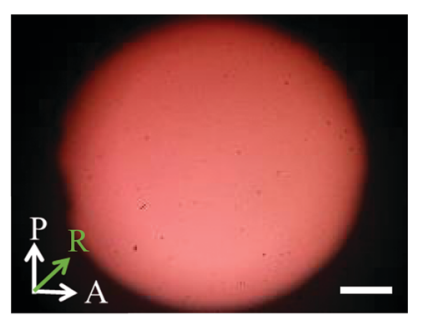

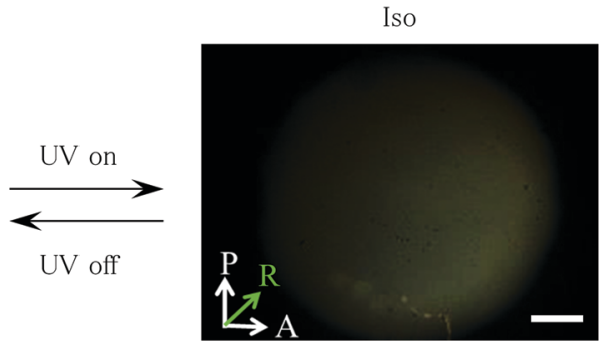

N

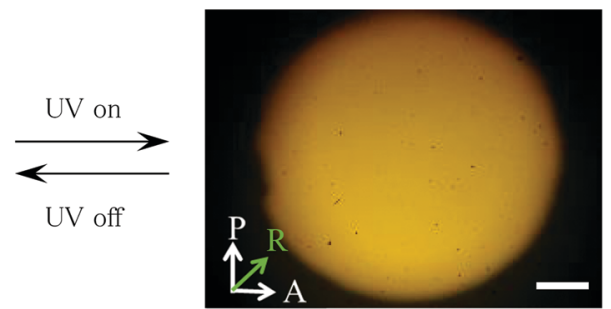

Fig. 7 Optical textures of: (a) a mixture of trimer I ( $20 \mathrm{wt} \%$ ) and compound II ( $80 \mathrm{wt} \%$ ) in a $5 \mu \mathrm{m}$ homogeneously aligned cell before and after $365 \mathrm{~nm}$ UV irradiation at $20 \mathrm{~mW} \mathrm{~cm}^{-2}$ in the $\mathrm{N}$ phase at $153.5^{\circ} \mathrm{C}$ and (b) at $114.2^{\circ} \mathrm{C} . R$ indicates the rubbing direction. Scale bars correspond to $500 \mu \mathrm{m}$.

at $78.9{ }^{\circ} \mathrm{C}$ (Fig. 8(a)). The $\mathrm{X}$ phase changed to a new texture in $60 \mathrm{~s}$ (Fig. 8(b)). When UV light was turned off, the texture was spread gradually but the $\mathrm{N}$ phase remained (Fig. 8(c)). It took about five minutes to reach an equilibrium state after UV light was turned off. The photo-induced texture change is irreversible. (a)

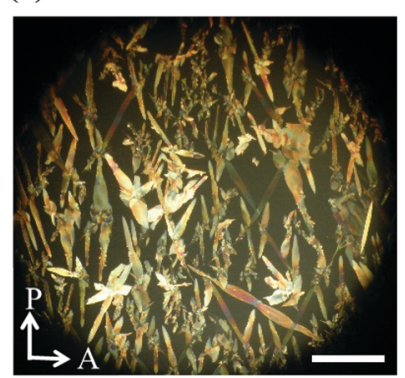

(c)

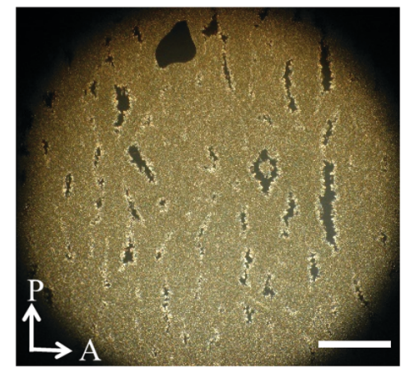

(b)

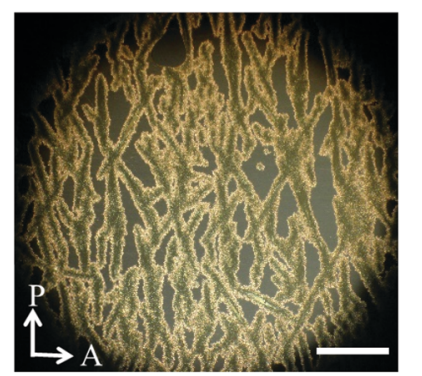

(d)

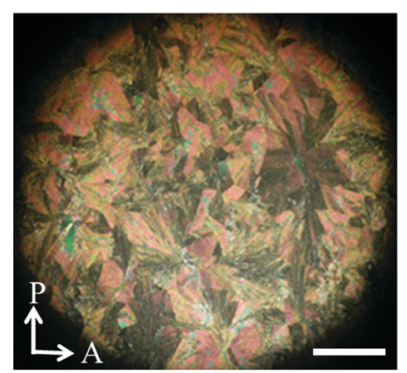

Fig. 8 Optical texture of: (a) a mixture of trimer I (20 wt\%) and compound II (80 wt\%) in the coexistence of the $\mathrm{N}$ and $\mathrm{X}$ phases at $78.9^{\circ} \mathrm{C}$, (b) mixture with $365 \mathrm{~nm}$ UV irradiation at $20 \mathrm{~mW} \mathrm{~cm}^{-2}$ at $76.4{ }^{\circ} \mathrm{C}$, (c) mixture 5 minutes after turning off the UV light, and (c) mixture in the crystalline phase at $40.3^{\circ} \mathrm{C}$. The sample was confined to a $5 \mu \mathrm{m}$ homogeneously aligned cell. Scale bars correspond to $500 \mu \mathrm{m}$.
On further cooling, the remaining $\mathrm{N}$ phase changed to the SmC phase at $70.8{ }^{\circ} \mathrm{C}$, also see Fig. S4 (ESI $\dagger$ ). The photo-induced phase and the SmC phase were crystallized at $41.9{ }^{\circ} \mathrm{C}$. When the sample exhibiting coexistence of the SmC and Y phases were irradiated with UV light, no marked change was observed in their textures. The photochemical effects were also observed for the mixture on a glass plate without surface treatment.

We observed the phase transition behaviour of the mixture confined in a $5 \mu \mathrm{m}$ homogeneously aligned cell on cooling from the isotropic liquid with $365 \mathrm{~nm}$ UV irradiation at a power of $20 \mathrm{~mW} \mathrm{~cm}^{-2}$. The $\mathrm{N}$ phase appeared at $153.1{ }^{\circ} \mathrm{C}$. The $\mathrm{X}$ phase observed for the mixture without UV irradiation did not appear. Then a smectic-like phase appeared at $68.9{ }^{\circ} \mathrm{C}$. The $\mathrm{N}$ and smectic-like phases coexisted in a temperature range of $19 \mathrm{~K}$. The wide temperature range is attributed to the mismatch in the molecular length between trimer I and compound II. Optical textures of the smectic-like phase are shown in Fig. 9. When the sample was rotated between crossed polarizers, bright and dark domains appeared. By rotating the sample in the opposite directions by the same angle, the darker and brighter domains were exchanged. These indicate that the director is tilted with the rubbing direction. The lowtemperature phase is thought to be a SmC phase originating from compound II. It was crystallized at $37.2{ }^{\circ} \mathrm{C}$.

Then we observed the phase transition behaviour of the mixture on a glass slide with a cover glass under the same conditions. On cooling from the isotropic liquid, the $\mathrm{N}$ phase appeared at $154.7^{\circ} \mathrm{C}$. With decreasing temperature, the texture became nearly dark with small bright spots (Fig. 10(a)). When the sample was rotated between crossed polarizers, the dark texture did not change. Therefore, the molecules are thought to be reoriented to align almost perpendicular to the glass substrate. Spherical nuclei were formed in the $\mathrm{N}$ phase at $65.8{ }^{\circ} \mathrm{C}$ 
(a)

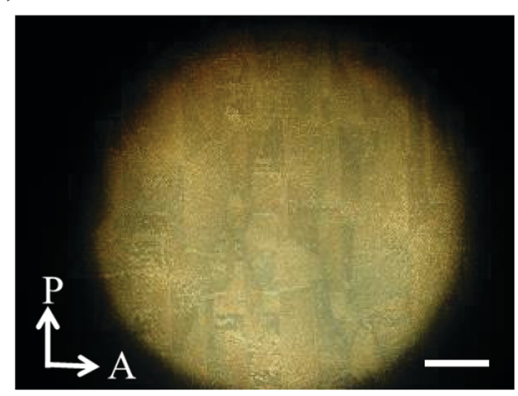

(b)

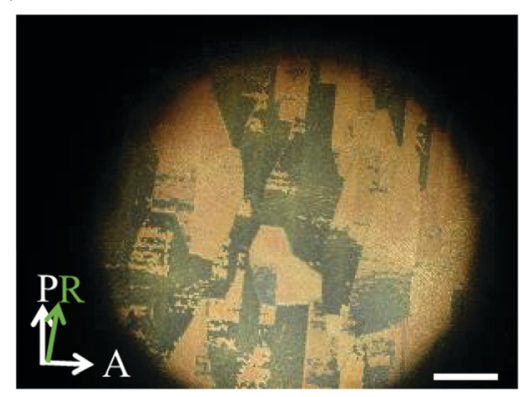

(c)

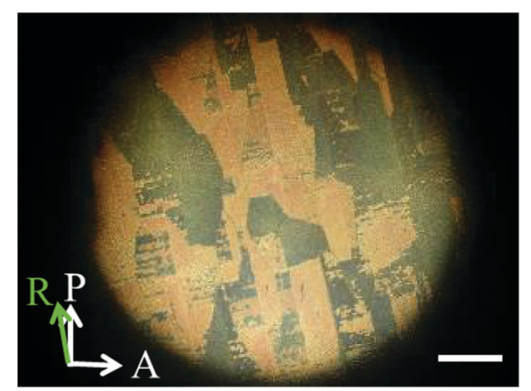

Fig. 9 Optical textures of the photo-induced phase of trimer I (20 wt\%) and compound II ( $80 \mathrm{wt} \%$ ) at $46.6^{\circ} \mathrm{C}$. The sample confined in a $5 \mu \mathrm{m}$ homogeneously aligned cell was cooled from the isotropic liquid with $365 \mathrm{~nm}$ UV irradiation at a power of $20 \mathrm{~mW} \mathrm{~cm}^{-2}$. $R$ indicates the rubbing direction. Scale bars correspond to $500 \mu \mathrm{m}$. (a) The rubbing direction is parallel to the polarizer, (b) the sample rotated clockwise from (a) and (c) the sample rotated anticlockwise from (a).

and they were spread radially. Based on the observation of the sample confined in a homogeneously aligned cell, it might be the SmC phase in which the molecules are aligned homotropically. Collision regions between different nuclei became blight gradually to form grain boundaries (Fig. 10(b)), also see Fig. S5 (ESI $\dagger$ ). Grain boundaries are usually observed for polycrystalline materials. The domain brightness did not change neither by rotation of the sample between the crossed polarizers nor by that of the analyzer as shown in Fig. 11, which indicates that the molecules orient quasi isotropically without forming a helical structure. Interestingly, schlieren texture can be seen in the grain boundaries as shown in Fig. 10(c), revealing that the nematic phase exists there. The texture as shown in Fig. 10(b) did not change when the UV light was turned off. The SmC phase accompanying the formation of grain boundaries consists of nematic liquid crystals changed to the crystalline phase at $37.4{ }^{\circ} \mathrm{C}$ (Fig. $10(\mathrm{~d})$ ).

We investigated how the external fields, i.e., UV irradiation and temperature, affect the formation of the grain boundaries. After the spherical nuclei began to form in the $\mathrm{N}$ phase, we observed the optical textures with UV irradiation at $61.9{ }^{\circ} \mathrm{C}$. They were spread without cooling as described above. However, when the UV light was turned off at $61.9^{\circ} \mathrm{C}$, the formed nuclei were not spread but many small nuclei appeared simultaneously to fill the space (Fig. S6, ESI $\dagger$ ). When the sample was cooled from the isotropic liquid with $365 \mathrm{~nm}$ UV irradiation at a power of $10 \mathrm{~mW} \mathrm{~cm}{ }^{-2}$, the $\mathrm{N}$ phase appeared at $154.8^{\circ} \mathrm{C}$. The SmC phase appeared at $69.1^{\circ} \mathrm{C}$. It is true that boundaries exist, but the boundary is not so distinct (Fig. 12).

\section{Models}

Let us discuss the photo-induced phase transitions of the binary system. According to semi-empirical calculations using MOPAC-6/PM3, we estimate the molecular shapes of trans- and cis-isomers of trimer I. Fig. 13 shows their MOPAC models with molecular length $(l)$ and width $(d)$. Based on the models, the $l / d$ ratios for trans- and cis-isomers are 10.3 and 3.6, respectively. It should be noted that the cis-form of azobenzene is twisted. The photo-induced transition between nematic and isotropic liquid, and that in nematic phases for the binary system are explained in terms of the $l / d$ ratios as follows. The photo-induced isomerization from trans-trimer I to cis-trimer I decreases the $l / d$ ratio, which decreases the order parameter in the $\mathrm{N}$ phase of the binary system. The appearance of the X phase without UV irradiation is attributed to the trans-isomer. The photo-induced trans-cis isomerization of trimer $\mathbf{I}$ is thought to have irreversible influence on the interactions between trimer I and compound II, producing the phase separation of the $\mathrm{N}$ phase and the photoinduced phase. It seems to be realistic that the photo-irradiation causes guest-host interactions such as "Command Surface"27,28 or "Sergeants and Soldiers effects". ${ }^{37,38}$ Fig. 14 shows a schematic model for the photo-induced transition.

Then we discuss how the grain boundaries are formed. According to the textures shown in Fig. 9, the lower temperature phase below the $\mathrm{N}$ phase is a synclinic SmC phase. However, no phase separation occurs for the mixture confined in a homogeneously aligned cell. Without surface treatment, the alignment of the liquid-crystalline molecules of the host is influenced by the shape of a large guest molecule through the guest-host interactions. In the $\mathrm{N}$ phase of the mixture under UV irradiation, cis-trimer $\mathbf{I}$ is thought to have a twist-bent shape, which can induce a bend deformation in the $\mathrm{N}$ phase through the guest-host interactions. Generally, a bend deformation in a smectic phase is forbidden because it prohibits the formation of a layer structure with a constant layer spacing. Trimer I might intercalate with the adjacent layers composed of host smectic molecules. Guest-host interactions between cores occur in each layer. The intercalated trimer I can cause strong correlation of motion and direction between the host cores in 
(a)

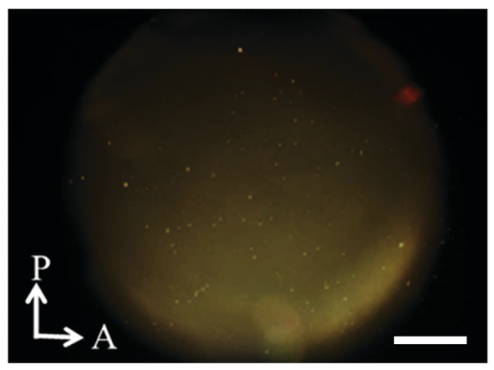

(c)

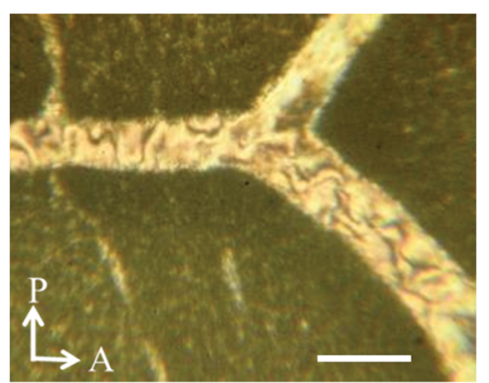

(b)

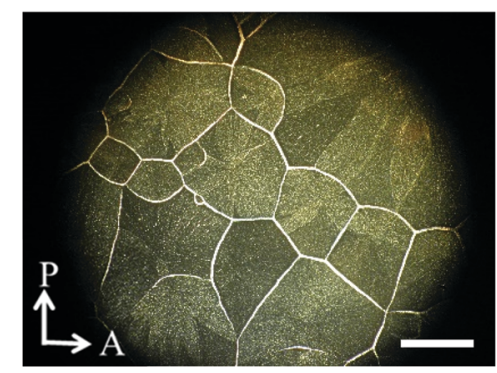

(d)

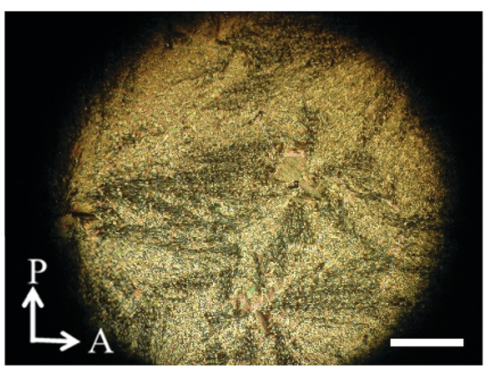

Fig. 10 Optical textures of a mixture of trimer I (20 wt\%) and compound II ( 80 wt\%) upon cooling using the isotropic liquid with 365 UV irradiation at a power of $20 \mathrm{~mW} \mathrm{~cm}{ }^{-2}$ between crossed polarizers. The sample was placed on a glass plate with a cover glass. Texture of: (a) the $\mathrm{N}$ phase at $75.0{ }^{\circ} \mathrm{C}$; (b) the SmC phase with grain boundaries at $49.6^{\circ} \mathrm{C}$; expansion of: (c) the grain boundaries of (b), and (d) crystal at $36.3^{\circ} \mathrm{C}$. Scale bars in (a), (b) and (d) correspond to $500 \mu \mathrm{m}$. The scale bar in (c) represents $50 \mu \mathrm{m}$.

(a)

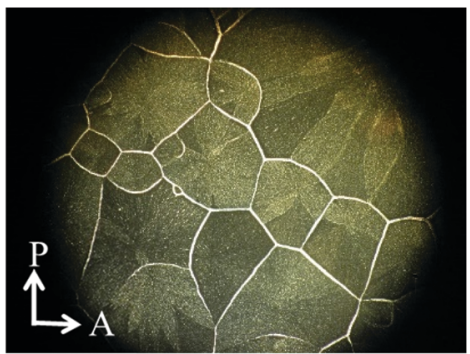

(c)

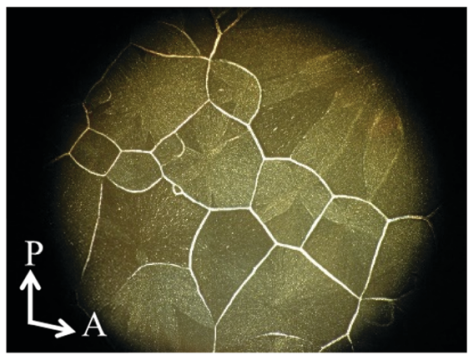

(b)

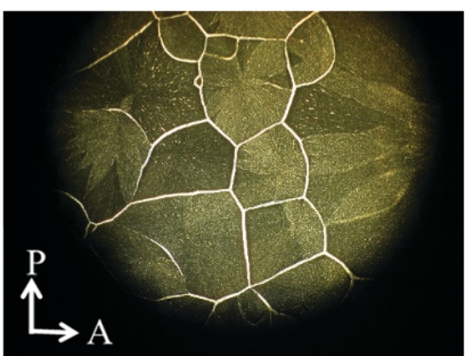

(d)

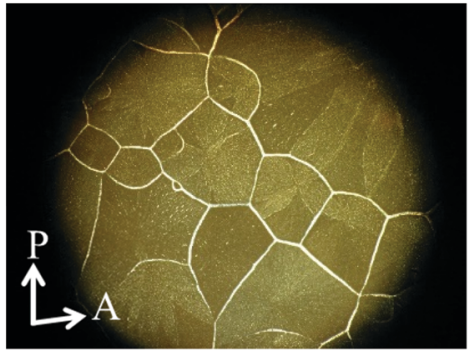

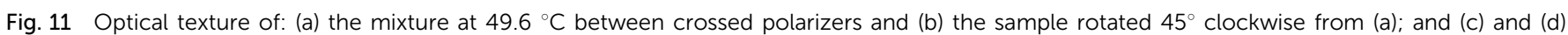
samples between uncrossed polarizers in the opposite direction.

adjacent layers. The relative directions of the two phenylpyrimidine cores of trimer $\mathbf{I}$ are dependent on the conformation of the central cis-azobenzene unit. The photo-induced cis-isomer forms a bent molecular shape with a twisted azobenzene unit.
Therefore, the twist-bent form of the cis-azobenzene unit is synchronized via cooperative motion of the core parts, which can preserve the bend deformation even in the SmC phase. The quasi isotropic texture without helicity as shown in Fig. 9 


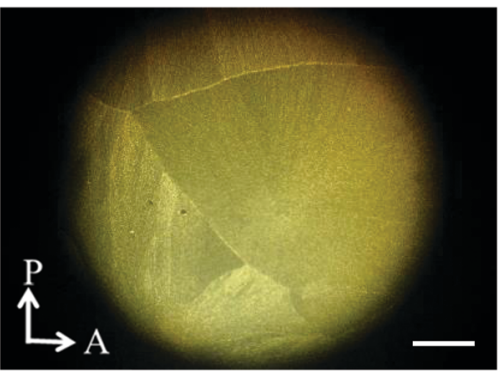

Fig. 12 Optical texture of the photo-induced phase at $61.2{ }^{\circ} \mathrm{C}$. The sample on a glass slide with a cover glass was cooled from the isotropic liquid with $365 \mathrm{UV}$ irradiation at a power of $10 \mathrm{~mW} \mathrm{~cm} \mathrm{~cm}^{-2}$. The scale bar corresponds to $500 \mu \mathrm{m}$.

indicates that bend and/or partially twist deformations without producing a helical structure exist in the SmC phase. On the other hand, liquid-crystalline molecules prefer to fill the space uniformly. Thus, the competition between the bend deformation and the formation of a layer structure leads to the formation of grain boundaries between smectic blocks as predicted by de Gennes. ${ }^{5}$ Some host liquid-crystalline molecules are recognized as impurities in the SmC phase and they are driven from the smectic blocks to the grain boundaries. They form a nematic organization at the grain boundaries. With the surface treatment, the alignment layer affects the orientation of the host liquid-crystalline molecules more strongly than trimer I. Therefore, the bend deformation is not induced in the homogeneously aligned SmC phase. Fig. 15 shows a schematic model for the formation of the grain boundaries. Although we do not have an experimental proof that the bend deformation exists in the SmC phase at present, we can say that the photo-induced bent-shaped trimer produces the SmC phase accompanying the formation of grain boundaries without chirality.

\section{Conclusions}

The newly designed symmetric trimer possessing an azobenzene unit exhibits the photo-induced isothermal crystal to

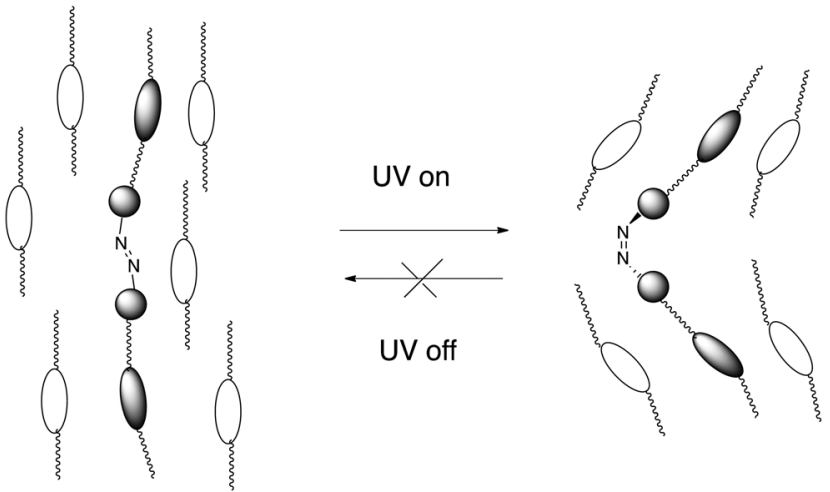

Fig. 14 Model for the photo-induced transition from the $X$ phase to another structure.

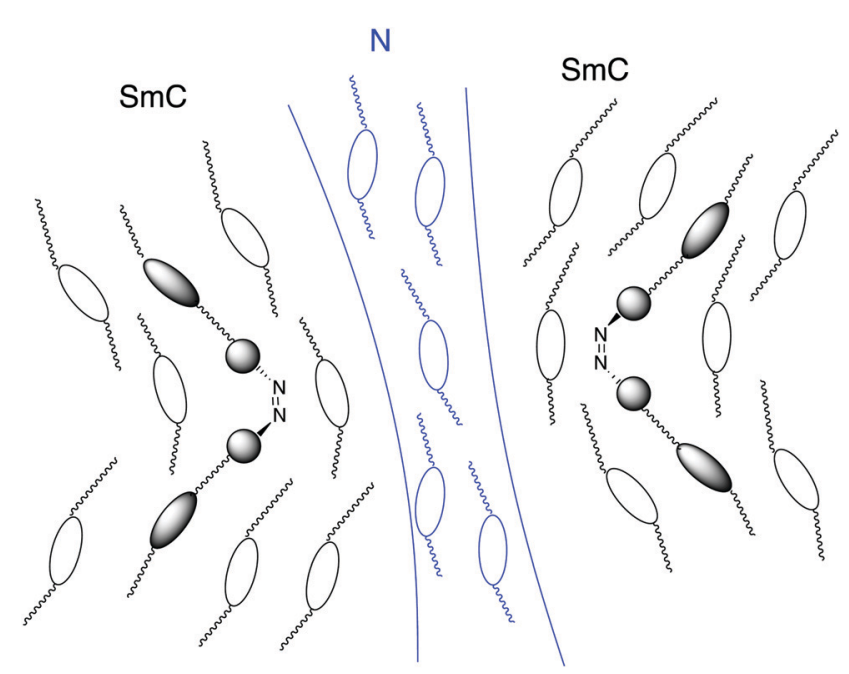

Fig. 15 Model for the formation of the grain boundaries for a mixture of trimer I (20 wt\%) and compound II ( $80 \mathrm{wt} \%$ ) during the cooling process with UV irradiation.

liquid transition through the trans-cis isomerization of azobenzene. The binary mixture with a host liquid crystal without
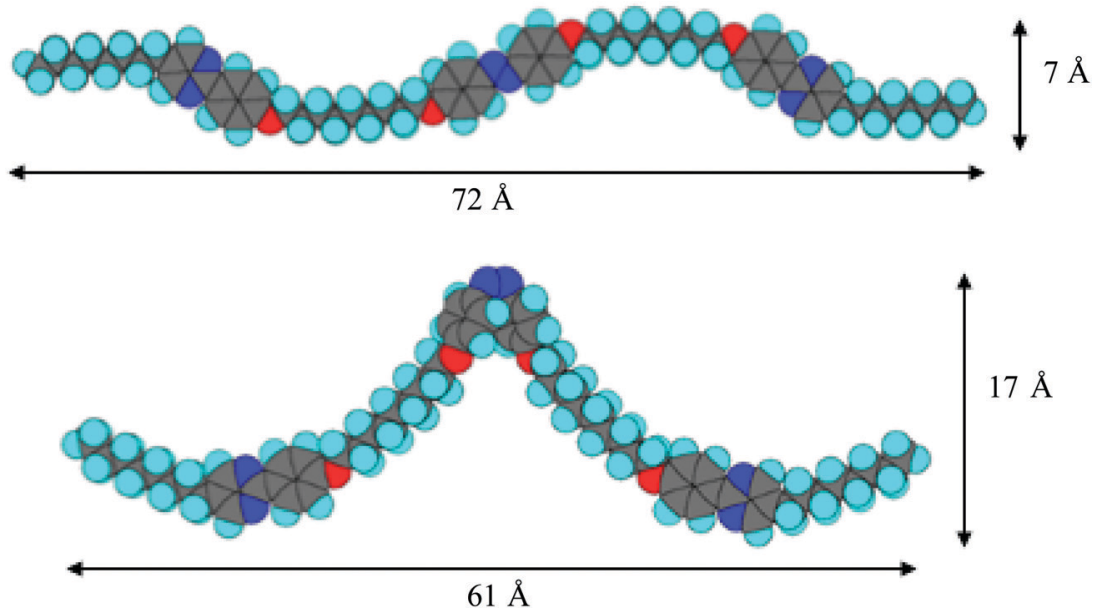

Fig. 13 MOPAC models for trans- and cis-isomers of trimer I. 
surface treatment exhibits a SmC phase with grain boundaries in which nemtaic liquid-crystalline molecules exist during a cooling process under UV irradiation. The photo-induced cistrimer affects the orientation of the host molecules in the SmC phase to produce deformations. As a consequence, grain boundaries consisting of nematic liquid crystals appear between the SmC blocks.

\section{Conflicts of interest}

There are no conflicts to declare.

\section{Acknowledgements}

We would like to thank Ms Michiko Yamaguchi, Ms Misaki Kurata, Mr Hideaki Sasaki and Ms Hitomi Betsumiya of Hirosaki University for their technical support.

\section{References}

1 J. D. Gunton, M. San Miguel and P. S. Sahni, The dynamics of first order phase transitions in Phase transitions and critical phenomena, ed. C. Domb and J. L. Lebowitz, Academic, London, 1983, vol. 8, pp. 269-466.

2 A. Onuki, Phase transition dynamics, Cambridge University Press, Cambridge, 2002.

3 H. Tanaka, Phys. Rev. Lett., 1993, 71, 3158.

$4 \mathrm{H}$. Tanaka, Phase separation in soft matter: concept of dynamic asymmetry, arXiv: 1307.1518vl [cond-mat. soft].

5 P. G. de Gennes, Solid State Commun., 1972, 10, 753.

6 S. R. Renn and T. C. Lubensky, Phys. Rev. A: At., Mol., Opt. Phys., 1988, 38, 2132.

7 J. W. Goodby, M. A. Waugh, S. M. Stein, E. Chin, R. Pindak and J. S. Patel, J. Am. Chem. Soc., 1989, 111, 8119.

8 J. W. Goodby, M. A. Waugh, S. M. Stein, E. Chin, R. Pindak and J. S. Patel, Nature, 1989, 337, 449.

9 M. Cestari, S. Diez-Berart, D. A. Dunmur, A. Ferrarini, M. R. de La Fuente, D. J. B. Jackson, D. O. Lopez, G. R. Luckhurst, M. A. Perez-Jubindo, R. M. Richardson, J. Salud, B. A. Timimi and H. Zimmermann, Phys. Rev. E: Stat., Nonlinear, Soft Matter Phys., 2011, 84, 031704.

10 V. Borshch, Y.-K. Kim, J. Xiang, M. Gao, A. Jakli, V. P. Panov, J. K. Vij, C. T. Imrie, M. G. Tamba, G. H. Mehl and O. D. Lavrentovich, Nat. Commun., 2013, 4, 2635.

11 D. Chen, J. H. Porada, J. B. Hooper, A. Klittnick, Y. Shen, M. R. Tuchband, E. Körblova, D. Bedrov, D. M. Walba, M. A. Glaser, J. E. Maclennan and N. A. Clark, Proc. Natl. Acad. Sci. U. S. A., 2013, 110, 15931.
12 I. Dozov, Europhys. Lett., 2001, 56, 247.

13 P. A. Henderson and C. T. Imrie, Liq. Cryst., 2011, 38, 1407. 14 D. Chen, M. Nakata, R. Shao, M. R. Tuchband, M. Shuai, U. Baumeister, W. Weissflog, D. M. Walba, M. A. Glaser, J. E. Maclennan and N. A. Clark, Phys. Rev. E: Stat. Phys., Plasmas, Fluids, Relat. Interdiscip. Top., 2014, 89, 022506.

15 S. M. Jansze, A. Martinez-Felipe, J. M. D. Storey, A. T. M. Marcelis and C. T. Imrie, Angew. Chem., Int. Ed., 2015, 54, 643.

16 R. J. Mandle, Soft Matter, 2016, 12, 7883.

17 J. P. Abberley, R. Killah, R. Walker, J. M. D. Storey, C. T. Imrie, M. Salamonczyk, C. Zhu, E. Gorecka and D. Pociecha, Nat. Commun., 2018, 9, 228.

18 H.-S. Kitzerow, Chirality in Liquid Crystals, ed. H.-S. Kitzerow and C. Bahr, Springer, New York, 2001, ch. 10, p. 296.

19 H.-S. Kitzerow, Mol. Cryst. Liq. Cryst., 2004, 412, 103.

20 A. Yoshizawa, H. Kikuzaki and M. Fukumasa, Liq. Cryst., 1995, 18, 351.

21 A. Yoshizawa, J. Mater. Chem., 2008, 18, 2877.

22 A. Yoshizawa, Liq. Cryst., 2017, 44, 1877.

23 A. Yoshizawa and I. Nishiyama, J. Mater. Chem., 1994, 4, 449.

24 S. Tazuke, S. Kurihara and T. Ikeda, Chem. Lett., 1987, 911.

25 T. Ikeda and O. Tsutsumi, Science, 1995, 268, 1873.

26 T. Ikeda, J. Mater. Chem., 2003, 13, 2037.

27 K. Ichimura, Y. Suzuki, T. Seki, A. Hosoki and K. Aoki, Langmuir, 1988, 4, 1214.

28 K. Ichimura, Chem. Rev., 2000, 100, 1847.

29 Y. Okui and M. Han, Chem. Commun., 2012, 48, 11763.

30 E. Uchida, K. Sasaki, Y. Nakamura, R. Azumi, Y. Hirai, H. Akiyama, M. Yoshida and Y. Norikane, Chem. - Eur. J., 2013, 19, 17391.

31 O. S. Bushuyev, A. Tomberg, T. Friscic and C. J. Barrett, J. Am. Chem. Soc., 2013, 135, 12556.

32 W.-C. Xu, S. Sun and S. Wu, Angew. Chem., Int. Ed., 2019, 58, 9712.

33 H. Nakano, S. Seki and H. Kageyama, Phys. Chem. Chem. Phys., 2010, 12, 7772.

34 K. Uchida, N. Nishikawa, N. Izumi, S. Yamazoe, H. Mayama, Y. Kojima, S. Yokojima, S. Nakamura, K. Tsuji and M. Irie, Angew. Chem., Int. Ed., 2010, 49, 5942.

35 H. Akiyama and M. Yoshida, Adv. Mater., 2012, 24, 2353.

36 M. Fukui, K. Kitano, M. Tanaka and Y. Goto, EP0104011A1, 1983.

37 M. M. Green, M. P. Reidy, R. D. Johnson, G. Darling, D. J. O'Leary and G. Willson, J. Am. Chem. Soc., 1989, 111, 6452.

38 M. M. Green, J. W. Park, T. Sato, A. Teramoto, S. Lifson, R. L. B. Selinger and J. V. Selinger, Angew. Chem., Int. Ed., 1999, 38, 3139. 